\title{
CAMBRIDGE
}

\section{Mind in Science}

\section{Richard L. Gregory}

Gregory traces the development of modern scientific concepts from the Sumerians and the Greeks on, and charts the growth of psychology in man's attempts to relate Mind to Matter. He ultimately suggests that such recent efforts as attempts to design intelligent machines may provide new answers to the riddle of the phenomenon of knowledge.

$\$ 29.95$

\section{Human Groups and Social Categories}

Studies in Social Psychology Henri Tajel

A volume chronicling the progress of Tajfel's work on relations among, and conflicts between, groups. Tajfel has played a central role in the development of social psychology in Europe over the last twenty-five years.

"These essays are more than an expression of the creative talents of Tajfel. They are also a sensitive testament to the times in which he has lived and in which the social sciences have grown."-from the foreword by Jerome Bruner Hardcover $\$ 54.50$ Paper $\$ 17.50$

\section{Time-Series Analysis}

A Comprehensive Introduction

for Social Scientists

John M. Gottman

A practical and complete presentation of all the major time-series techniques, both time-domain and time-frequency, for social scientists who need to analyze data over time Presupposes only basic introductory statistics; requires no calculus.

$\$ 24.95$

\section{The Meaning of Things}

\section{Symbols in the Development of Self} Mihaly Cslkszentmihalyi and Eugene Rochberg-Halton

A remarkable study of the significance of material possessions in contemporary urban American life, and the ways people find meaning in their domestic environments.

"The book has no parallels. It is highly original and important... moves surefootedly over a vast intellectual terrain." - M. Brewster Smith, University of California, Santa Cruz $\$ 22.50$

\section{Behavioral Development}

The Bielefeld Interdisciplinary Project Klaus Immelmann, George W. Barlow, Lewis Petrinovich, and Mary Biggar Main, Editors

This collection of essays by a distinguished group of psychologists, zoologists, neurologists, and psychiatrists represents the first major attempt to remove disciplinary barriers to create a common framework for the analysis of behavioral development in humans and other animals.

Hardcover $\$ 59.50$ Paper $\$ 18.95$ of methodological interest

\section{Estimating the Effects of Social Interventions}

Charles M. Judd and David A. Kenny A comprehensive introduction to methods for measuring the impact of social interventions in a variety of experimental and field settings-for example, education, mental health care, and income maintenance.

Hardcover $\$ 32.50$ Paper $\$ 12.95$

\section{Sigmund Freud} Richard Wollheim

Other Books of Interest

\section{Child Language}

Alison Elliot Hardcover $\$ 29.95$ Paper $\$ 8.95$

\section{The Development of}

\section{Children's Friendships}

Steven R. Asher and John M. Gottman, Editors

\section{Social Contexts of Health,} IIIness, and Patient Care Elliot G. Mishler, Editor

Hardcover \$24.95 Paper \$10.95

\section{Social Cognitive Development Frontiers and Possible Futures John H. Flavell and Lee Ross, Editors}

Hardcover $\$ 32.50$ Paper $\$ 12.95$ 


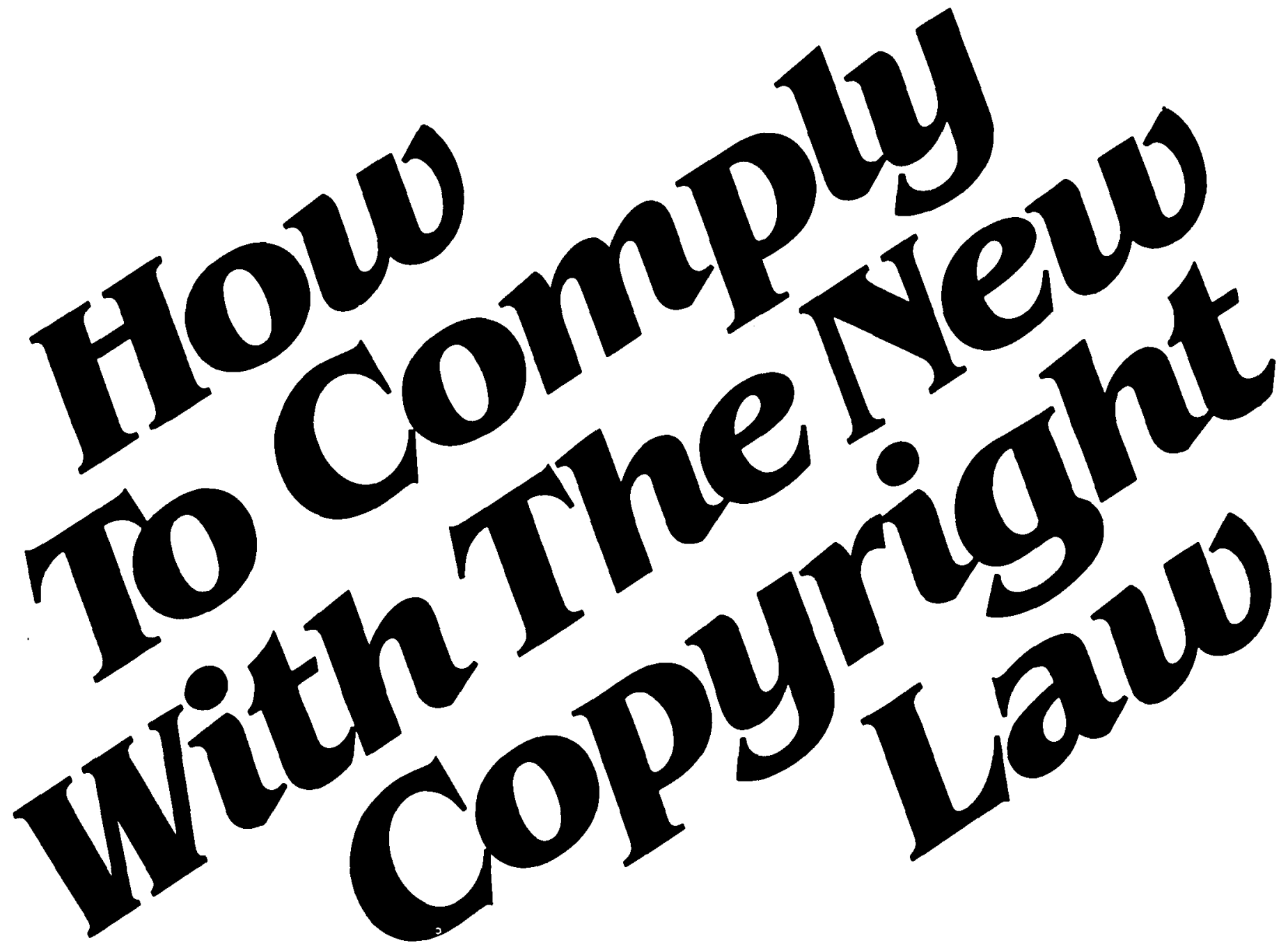

Participation in the Copyright Clearance Center (CCC) assures you of legal photocopying at the moment of need.

Libraries everywhere have found the easy way to fill photocopy requests legally and instantly, without the need to seek permissions, from more than 3000 key publications in business, science, humanities, and social science. You can:

Fill requests for multiple copies, interlibrary loan (beyond the CONTU guidelines), and reserve desk without fear of copyright infringement.

Supply copies from CCC-registered publications simply and easily.

The Copyright Clearance Center is your one-stop place for on-the-spot clearance to photocopy for internal use.

Its flexible reporting system accepts photocopying reports and returns an itemized invoice. You send only one convenient payment. CCC distributes it to the many publishers whose works you need
And, you need not keep any records, the CCC computer will do it for you. Register now with the $\mathrm{CCC}$ and you will never again have to decline a photocopy request or wonder about compliance with the law for any publication participating in the CCC.

To register or for more information, just contact:

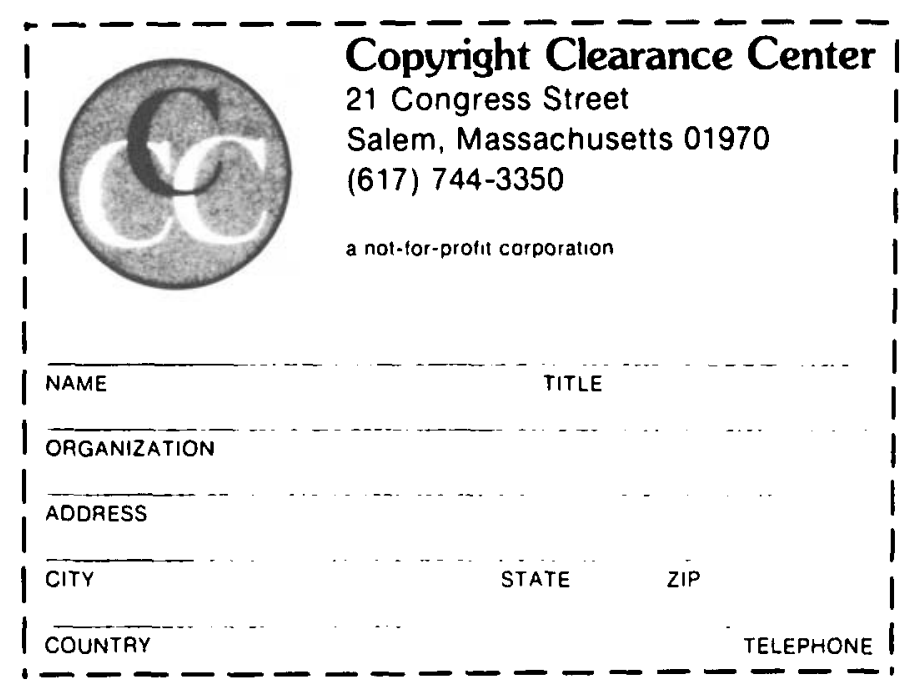




\section{The Behavioral and Brain Sciences}

\section{Instructions to Authors and Commentators}

THE BEHAVIORAI. AND BIIAIN SCIENCES (BBS) is a unique scientific communication medium. providing the service of Open Peer Commentary fot reports of significant current work in any area of psychology, neuraseience, behavioral biology or cognitive seience. If a subsitted manuscript is judged by BBS referees and editors to be appropriate for Commentary (see Criteria below), it is then circulated to a large number of commentators selected (with the aid of systematic biblingraphie searches) from the BBS Associateship" and the worldwide biobehavioral science cornmunity, including individuals recommended by the anthor

Once the Commentary stage of the process has begun, the author can no longer ater lis article. but he can respond formally to all commentaries accepted for publication. The target article, commentaries and author's response then co-appear in BBS. Continumg Commentary and replies can appear in later issues

\section{Criteria for acceptance}

Ta be etigible for publication, a paper should not anly meet the standards of a journal such as Psychological Review or the Inturnationul Review of Neurobio. logy in terms of conceptual rigot, empirical grounding and clarity of style, but it should atwo offer a clear rationale for soliciting Commentary. That rationale should be provided in the author's eovering letter. together with a list of suggested commentators. The original manuscript plus eight eopies must be submitted.

A paper for HBS can be (1) the report and discussion of empirical research thiat the author judyes to have brader scope and implications than might be more appropriately reported in a specialty journal: (2) an unusually significant theoretical articie that formally models of systematizes a body of research; o (3) a novel interpretation. svnthesis, or critique of existing experimental or theoretical work Occasionally, articles dealing with social or philosophical aspects of the behaviorat and hran sciences will be considered

The service of Open Peen Commentary will be primarily devoted to origina unpublished mamiscripts However, a recently published bonk whose content: meet the standards ontlined atove is also eligible for Commentary if the author submits a comprehensive, article-length précis to be published together with the conmentaries and his response In special cases, Commentary will also be extended to a position paper or an already published article dealing with particularly inflecritial or controversial research Submission of an artick implies that it has not been puthlished or is not being considered for publication elsewhere, Anthors submitting previously published articles for consideration should give full information of place of publication, date, and include permis. sion from the copyright holder ke reprint. The Associateship and professional readership of BBS are encouraged to nominate current topies and authors for Comuentary.

fu all the categories described the decisive consideration for eligibility wil be the desirability of Commentary for the contents of the submitted material Contmversiality simpliciter is not a sufficient criterion far soliciting Commentary: a paper may be controversial simply because it is wrong or weak. Nor is the mere presence of interdisciplinary aspects sufficient gerneral cybernetic and "nrganismic" disquistiuns are not appropriate for BBS. Some appropriate tationales for seeking Open Peer Cormmentary would be that.

- the material hears in a significant way on some current controversial issues is behavioral and brain science:

- its findings substantivedy contradict sume well-established aspects of current research and theory.

- it criticiess the findings, practices, or princtples of an accepted or influential line of worl.

- it unifies a substantial amnunt of disparate research:

- it has important cross-disciplinary ramifications;

- it introduces an itunvative melhodology or formalism for consideration by proponients of the extablished forms.

- it significantly integrates a body of brain and behavioral daka

- it places a hitherto dissociated area of research into an evolutionary or ecological perspective; cte

in order to assure communication with potential commentators fand readers) from other BBS specialty areas, all technical terminology must be clearly defined or simplified, and speciatized concepts must be fully described.

\section{Note to commentators}

The purpose of the Open Peer Commentary service is to provide a concentrated constructive interaction between author and cormmentators on a topic judged to be of broxd significance to the biobehavioral science community. Commentators hould provide sulbstantive crilicism, interpretation, and claboration as well as any pertinent complementary or supplementary material, such as illustrations: all origimal data will be refereed in order to assure the archival validity of BHS commentaries. Commentarios and articles should be free of hyperbole and remarks ad hominum

\section{Style and format for articles and commentaries}

Articles must not exceed 14,000 words fand should ordinarily be considerably shorter); commentaries should not exceed 1,000 words. Spelling, capilatization, and punctuation should be consistent within each article and commentar and should follow the style recommended in the latest edition of A Mantual of Style, The University of Chicago Press. It may be helpfitl to examine a recent issue of BBS. A title should be given for each article and commentary At auxiliary short title of 50 or fewer characters should be given for any article whose tille exceeds that length. Fach commentary must have a distinctive. representative commentary title. The contributor's name should be given in the form preferred for publication: the affiliation should include the full institutional address. Two abstraets, one of 100 and one of 250 words, should to submitted with every article. The shorter abstract will appear one issite in advance of the article; the longer one will be circulated to potential commentators and will appear with the printed article. A list of 5-10 keywords should precede the text of the article. Tables and figures (i.e. photographs, graphs. dharts, or other anwork) should be numbered consecutively in a separate series. Every table and figure should have a title or caption and at least one reference in the text to indicate its appropriate location. Notes, acknowledgements appendixes, and references should be grouped at the end of the article or commentary. Bibliographie citations in the text must include the author's las name and the date of publication and may inciude page references. Complete bibliographic information for each citation shorid be inclucled in the list of references. Examples of eorrect style for bibliographic citations are Brown (1973); (Brown 1973), (Brown 1973; 1978), (Brown 1973), Jones 1976). (Brown \& Jones 1978), (Brown, Jones \& Smith 1979) and subsequently. (Brown et al 1979). References should be typed in uphabetical order in the style of the following examples

Kupfermann, I. \& Weiss, K. (1978) The command neuron concept. The Behavioral and Brain Sciences 1:8-39.

Dunn. I (1976) How far do early differences in mother-child relations affer: later developments? In Crouing points in ethology, ed. P P G. Baleson \& R. A Hinde; PP. 1-10. Cambridge: Cambridge University Press:

Bateson. P P. G. \& Finde, B A, eds. (1976) Growing points in ethology Cambridge: Cambridge University Press.

Journal titles should not be abbrevialed.

\section{Preparation of the manuscript}

The entire manuseript, including notes and meferences, must be typed double. spaced on $81 / 2$ by 11 inch or A4 paper, with margins sel to accommodate approximately 70 characters per line and 25 lines per paze. and should net exceed 50 pages. Pages should the numbered cotiseculively. If will be nevessary to return manuseripts for retyping if they do not conform to thisstandard

Fach lable and figure: should be submitued on a separate page, not interspersed with the text. Tables should be typed to conform to BBS style Figures stould be ready for photographic reproduction; they cannot be redraws by the printer. Charts, graphs or other artwork should be done in black ink on white paper and should be drawn to occupy a standard area of $8 \%$ by 11 or $81 / 2$ by $5 \%$ inches before reduction. Photographs should be gloasy black-and-white prints: 8 by 10 inch eniargemenis are vreferred. $A l l$ labels and details on figures should be clearly printed and large enouglt to remain legible even after a reduction to half size. It is recommended that labels be done in transfer type of a sans-serif face such as Helvetica.

Authors are requested to submit their original manuscript with eight copie: for refereeing and commentators their original plus two copies, to: Stevan Harnad, Editor. The Behavioral and Brain Seiences, PO: Box 777, Princeton. N.J. 08540.

\section{Editing}

The publishers reserve the right to edit and proof all articles and commentaries accepted for publication. Authors of articles will be given the opportunity to review the copyedited manuscript and page proofs. Commentators will be: asked to review copyediting only when changes have been substantial. commentators will not see proofs. Both authors and commentators should notify the editorial affice of all eorrections within 48 hours or appraval will be assumed.

Authors of target articles will receive 50 offprints of the entire treatment, and can purchase additional copirs. Commentators will also be given an opportanily to purchase offprints of the entire treatment

Fualified professionals in the behavioral and brain sciences who have either (1) been nominated by a current BBS Associate, (2) refereed for BBS, or (B) had a commentary or article accepted for publication can become BBS Associates. Editors of learned journals and officers of seientifie societies are invited to become BBS Asscociates ex officio for liaison purposes. Asociates are eligible for a reduced subscription rate. Please write to the Editor for further information 


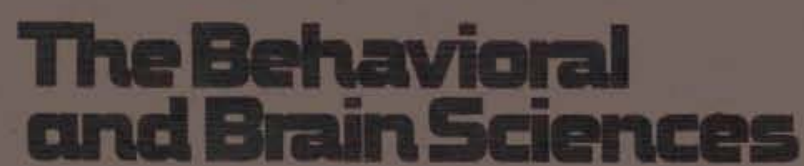

\section{To appear in Volume 4, Number 4 (1981)}

Offprints of the following forthcoming BBS treatments can be purchased in quantity for educational purposes if they are ordered well in advance. For ordering information, please write to Journals Department, Cambridge University Press, 32 East 57 th Street, New York, N.Y. 10022

\begin{abstract}
Modeling a paranoid mind
Kenneth Mark Colby, University of California, Los Angeles

As one of the cognitive sciences, artificial intelligence attempts to model a variety of psychological processes. One of these efforts consists of modeling the psychopathological processes involved in the paranoid mode of thought. This article describes in some detail the workings of a model for paranoia known as PARHY. The evaluation of the model by Turing-like tests is discussed, along with a number of general problems regarding model construction.
\end{abstract}

With Commentary from R. P. Abelson, J Agassi. J. G. Carbonell. K. Gunderson, C. E. Izard \& F. A. Masterson, M. Kochen, P. A. Magaro \& H. G. Shulman, B. A Maher, K. Oatley, W. H. Reid \& J. F. Riedler, R. Revlin, A. Stoman, and others.

\section{Précis of The organization of action: A new synthesis \\ C. R. Gallistel, University of Pennsylvania}

In The organization of action (Hillsdale, N.J : Lawrence Eribaum Associates, 1980), principles are given for distinguishing complex from elementary units of behavior, and for distinguishing three kinds of elementary umits - the reflex, the oscillator, and the servomechanism. Principles for the intralevel and interlevel coordination of elementary and complex units are described. Out of this grows a theory of motivation along the lines of traditional ethological theory. The role of representations in learned behavior is discussed, as is the problem of how selected representations may be translated into action. Fourier models for the representation of learned-movement trajectories and for the representation of space are put forward to illustrate the possible advantages of representation by means of nonobvious decompositions.

With Commentary from M. A. Arbib, R. C. Bolles; B. Craske, R. W. Doty, S. Grillner, J.A. Hogan, J. M. Hollerbach. R. Jander, M. Jeannerod, E. R. Lewis, N. J. Mackintosh, P. M. Milner, A Newell, D. S. Olton. H L. Roitblat, and others

\begin{abstract}
The metabolic basis of dual periodicity of feeding in rats

Jacques Le Magnen, Colliege de France

This article examines how the depletion and replenishment of various tody-energy stores stimulate periodic cating and how constant body-energy content is maintained over time. An interaction between glucoregulatory and liporegulatory systems appears to be involved in the control of two superimposed feeding palterns and in the overall regulation of body energy
\end{abstract}

With Commentary from D, A. Booth, R. C. Casper \& R. F. Schlemmer. I. M. de Castro, I P. Flatt. R. B. Kanarek. N. Mrosovsky A. A. Nunez, J. Panksepp, R. C. Ritter, A. Sclafani, E. M. Stricker F. M. Toates, R. A. Vigersky, R J, Wakbillig, and others

Does play matter? Functional and evolutionary aspects of animal and human play

Peter K. Smith, University of Sheffield

The adaptive value of animal play is considened in terms of its conts and benefits to inclusive fitness. Play functions primarily to provide juveniles with practice for later skills when such practice would otherwise be unlikety or unsafe. This applies to physical training social competition, and (for a few species only) tool use. In hominids the capacity for fantasy may have been an emergent property which superimposed on an arousal mechanism. increased the complexity of their play: Cultural change and, in purticular, organised instruction have sinee radically modified the adaptive signifieance of contemporary human play.

With Commentary from I. D. Baldwin, M. Beknff, I. S, Bernstein. M. Csikszentmihalyi, 1. Eibl-Eibesfeldt, R. Fagen, G. G. Fein P. A. Ferehmin \& V. A. Eternvič, M. Lewis, B. E. Poirier H. B. Sehwartzman, B. Sutton-Sinith, B. Vandenberg, D. P Wolf and others

\section{Among the articles to appear in forthcoming issues of BBS:}

BBS Multiple Book Review of C. J. Lumsden \& E. O. Wilson's Genes, Mind, and Culture

H. Anisman \& R. M. Zacharko, "Depression: The predisposing influence of stress"

R. A. Wise, "Neurolepties and operant behavior: The anhedonia hypothesis"

H. L. Roitblat, "The meaning of representation in animal memory"

D. P. Peters \& S. J. Ceci, "Resubmitting previously published articles: A study of the journal review process in psychology

BBS Multiple Book Review of J. A. Gray's The Neuropsychology of Anxiety 